ARTICLE

Received 14 Nov 2012 | Accepted 2 Jan 2013 | Published 5 Feb $2013 \quad$ DOl: 10.1038/ncomms2436

\title{
Effect of iron oxidation state on the electrical conductivity of the Earth's lower mantle
}

V. Potapkin 1,2, C. McCammon², K. Glazyrin², A. Kantor ${ }^{1,2}$, I. Kupenko², C. Prescher², R. Sinmyo ${ }^{2}$, G.V. Smirnov ${ }^{3}$, A.I. Chumakov ${ }^{1,3}$, R. Rüffer ${ }^{1} \&$ L. Dubrovinsky ${ }^{2}$

Iron can adopt different spin states in the lower mantle. Previous studies indicate that the dominant lower-mantle phase, magnesium silicate perovskite (which contains at least half of its iron as $\mathrm{Fe}^{3+}$ ), undergoes a $\mathrm{Fe}^{3+}$ high-spin to low-spin transition that has been suggested to cause seismic velocity anomalies and a drop in laboratory-measured electrical conductivity. Here we apply a new synchrotron-based method of Mössbauer spectroscopy and show that $\mathrm{Fe}^{3+}$ remains in the high-spin state in lower-mantle perovskite at conditions throughout the lower mantle. Electrical conductivity measurements show no conductivity drop in samples with high $\mathrm{Fe}^{3+}$, suggesting that the conductivity drop observed previously on samples with high $\mathrm{Fe}^{2+}$ is due to a transition of $\mathrm{Fe}^{2+}$ to the intermediate-spin state. Correlation of transport and elastic properties of lower-mantle perovskite with electromagnetic and seismic data may provide a new probe of heterogeneity in the lower mantle.

\footnotetext{
${ }^{1}$ European Synchrotron Radiation Facility, BP 220, Grenoble F-38043, France. ${ }^{2}$ Bayerisches Geoinstitut, Universität Bayreuth, D-95440 Bayreuth, Germany

${ }^{3}$ National Research Center 'Kurchatov Institute', Moscow 123182, Russia. Correspondence and requests for materials should be addressed to C.M.

(e-mail: catherine.mccammon@uni-bayreuth.de).
} 
$\mathrm{P}$ ressure-induced spin transitions (that is, changes in the pairing of electrons in the atomic orbitals) of iron in lowermantle minerals can significantly influence mantle properties and dynamics. One factor that strongly influences the potential for a particular iron species to undergo a spin transition is its surrounding crystallographic environment. The structure of the Earth's most abundant phase, iron-containing magnesium aluminium silicate perovskite (hereafter referred to as FeAlPv), contains two sites, a large 8-12 coordinated site ('A') and a smaller octahedral site ('B'). At least half of the iron in FeAlPv in the lower mantle is expected to be $\mathrm{Fe}^{3+}$ (refs 1-3), which can occupy either the A site or the B site. The A site is additionally occupied primarily by $\mathrm{Mg}^{2+}$ and $\mathrm{Fe}^{2+}$, and the $\mathrm{B}$ site by $\mathrm{Si}^{4+}$ and $\mathrm{Al}^{3+}$. Previous studies of spin transitions of $\mathrm{Fe}^{3+}$ in FeAlPv are broadly consistent, and have shown that a high-spin (HS) (five unpaired $d$ electrons) to low-spin (LS) (one unpaired $d$ electron) transition is predicted when $\mathrm{Fe}^{3+}$ occupies the $\mathrm{B}$ site, whereas $\mathrm{Fe}_{\mathrm{A}}^{3+}$ (that is, $\mathrm{Fe}^{3+}$ in the A site) is predicted to remain in the HS state at all pressures throughout the lower mantle $e^{4-9}$, and several studies have additionally predicted exchange of $\mathrm{Fe}^{3+}$ from the $\mathrm{A}$ to the $\mathrm{B}$ site at pressures above the HS-LS transition ${ }^{6,8,9}$. The drop in electrical conductivity observed with increasing pressure ${ }^{10-12}$ has generally been attributed to a HS-LS transition of $\mathrm{Fe}^{3+}$. However, there are also reports of a transition of $\mathrm{Fe}^{2+}$ in FeAlPv that starts above $\sim 30 \mathrm{GPa}$, although there is disagreement as to whether it involves a HS (four unpaired $d$ electrons) to intermediate-spin (IS) (two unpaired $d$ electrons) transition $^{13-15}$ or simply a structural modification of the local atomic environment ${ }^{16}$.

Detecting spin transitions in FeAlPv presents a significant challenge. X-ray emission spectroscopy provides information on the bulk spin number, but cannot separate individual contributions. In contrast, energy-domain ${ }^{57} \mathrm{Fe}$ Mössbauer spectroscopy generally enables an unambiguous resolution of all hyperfine parameters, which can be used to infer spin states; however, high-pressure measurements using conventional radioactive point sources require extremely long counting times (generally more than 1 week per spectrum). Third-generation synchrotron sources offer a solution in the form of time-domain Mössbauer spectroscopy (that is, nuclear forward scattering); however, this method is not well suited to materials with a large number of components (such as FeAlPv) because of the resulting complex spectra. To solve this problem, we have developed an energydomain synchrotron Mössbauer source (SMS) that offers a number of advantages over conventional Mössbauer spectroscopy: high brilliance and a nearly fully resonant emitted beam that can be focused to a spot of only a few microns diameter, and in contrast to time-domain spectroscopy, spectra that deliver direct and unambiguous information ${ }^{17,18}$. Therefore, SMS spectroscopy allows for rapid measurement of energy-domain Mössbauer spectra under extreme conditions with a quality generally sufficient to unambiguously deconvolute even highly complex spectra.

In this study, involving SMS measurements over a wide range of FeAlPv compositions with varying $\mathrm{Fe}^{3+} / \Sigma \mathrm{Fe}$, we show that $\mathrm{Fe}^{3+}$ remains in the $\mathrm{HS}$ state at pressure-temperature conditions relevant for the lower mantle, whereas $\mathrm{Fe}^{2+}$ undergoes the same transition observed in previous experiments ${ }^{13-15}$. Combined with new high-pressure high-temperature electrical conductivity data on $\mathrm{Fe}^{3+}$-rich FeAlPv, we suggest that the drop in conductivity observed in previous experiments ${ }^{10-12}$ is due to the hotly disputed $\mathrm{HS}$ to IS transition in $\mathrm{Fe}^{2+}$. These results may place improved constraints on the interpretation of lower-mantle electrical conductivity profiles as well as of joint inversions of electromagnetic and seismic data, potentially providing a new probe for heterogeneity in the lower mantle.

\section{Results}

Sample synthesis and characterization. We studied four different FeAlPv samples: $\mathrm{Mg}_{0.6} \mathrm{Fe}_{0.4} \mathrm{Si}_{0.63} \mathrm{Al}_{0.37} \mathrm{O}_{3}$ sample no. 1 ( 80\% $\left.\mathrm{Fe}^{3+} / \Sigma \mathrm{Fe}\right) ; \mathrm{Mg}_{0.6} \mathrm{Fe}_{0.4} \mathrm{Si}_{0.63} \mathrm{Al}_{0.37} \mathrm{O}_{3}$ sample no. $2\left(\sim 70 \% \mathrm{Fe}^{3+} /\right.$ $\Sigma \mathrm{Fe}) ; \mathrm{Mg}_{0.83} \mathrm{Fe}_{0.2} \mathrm{Al}_{0.06} \mathrm{Si}_{0.91} \mathrm{O}_{3}\left(\sim 50 \% \mathrm{Fe}^{3+} / \Sigma \mathrm{Fe}\right)$ (sample no. 3); and $\mathrm{Mg}_{0.94} \mathrm{Fe}_{0.06} \mathrm{SiO}_{3}\left(\sim 20 \% \mathrm{Fe}^{3+} / \Sigma \mathrm{Fe}\right.$ ) (sample no. 4). Details of sample synthesis and characterization are summarized in Table 1.

Single-crystal X-ray refinements and crystal chemical calculations show that $\mathrm{Fe}^{3+}$ occupies predominantly the A site of the perovskite structure in all of our samples. Full structural refinements of a single crystal of FeAlPv synthesized using identical starting materials and experimental procedure to $\left(\mathrm{Mg}_{0.6} \mathrm{Fe}_{0.4}\right)$ $\left(\mathrm{Si}_{0.63} \mathrm{Al}_{0.37}\right) \mathrm{O}_{3}$ perovskite (sample no. 1 and 2) (with the exception that iron was not ${ }^{57} \mathrm{Fe}$ enriched) using in situ X-ray diffraction data collected in a diamond anvil cell (DAC) at pressures up to $80 \mathrm{GPa}$ and temperatures over $1700 \mathrm{~K}$ (ref. 19) showed that both $\mathrm{Fe}^{2+}$ and $\mathrm{Fe}^{3+}$ occupy the A site exclusively at all conditions studied. We therefore expect a similar site distribution for sample no. 1 and 2 in the current study. For $\mathrm{Mg}_{0.83} \mathrm{Fe}_{0.2} \mathrm{Al}_{0.06} \mathrm{Si}_{0.91} \mathrm{O}_{3}$ perovskite (sample no. 3), electron microprobe data combined with results from Mössbauer spectroscopy gave the following site distribution: $\quad\left[\mathrm{Mg}_{0.828(18)} \mathrm{Fe}^{2+}{ }_{0.104(13)} \mathrm{Fe}^{3+}{ }_{0.075(13)}\right]_{\mathrm{A}}\left[\mathrm{Si}_{0.911(23)}\right.$ $\left.\mathrm{Al}_{0.059(2)} \mathrm{Fe}^{3+}{ }_{0.029(13)}\right]_{\mathrm{B}} \mathrm{O}_{3}$. Iron occupies predominantly the $\mathrm{A}$

\begin{tabular}{|c|c|c|c|}
\hline Run number & S4850 & S4949 & S5083 \\
\hline Sample designation & No. 1 and 2 & No. 3 & No. 4 \\
\hline Starting material & $\mathrm{Mg}(\mathrm{OH})_{2}, \mathrm{SiO}_{2}, \mathrm{Al}_{2} \mathrm{O}_{3}, \mathrm{Fe}_{2} \mathrm{O}_{3}$ & $\mathrm{MgO}, \mathrm{SiO}_{2}, \mathrm{Al}_{2} \mathrm{O}_{3}, \mathrm{Fe}_{2} \mathrm{O}_{3}$ & $\mathrm{MgO}, \mathrm{SiO}_{2}, \mathrm{Fe}_{2} \mathrm{O}_{3}$ \\
\hline Temperature $\left({ }^{\circ} \mathrm{C}\right)$ & 1300 & 1800 & 1800 \\
\hline Run duration (min) & 30 & 30 & 50 \\
\hline Capsule & Pt & $\operatorname{Re}$ & $\operatorname{Re}$ \\
\hline \multicolumn{4}{|c|}{ Cation proportions (for $3 \mathrm{O}$ ) } \\
\hline $\mathrm{Mg}$ & $0.60(3)$ & $0.828(18)$ & $0.946(17)$ \\
\hline $\mathrm{Fe}$ & $0.40(3)$ & $0.208(13)$ & $0.056(12)$ \\
\hline $\mathrm{Al}$ & $0.37(2)$ & $0.059(2)$ & - \\
\hline $\mathrm{Si}$ & $0.63(3)$ & $0.911(23)$ & $0.997(16)$ \\
\hline $\mathrm{Fe}^{3+} / \Sigma \mathrm{Fe}$ & 0.80 (5) (sample no. 1) & $0.50(5)$ & $0.20(5)$ \\
\hline
\end{tabular}


site, although the presence of a small amount of $\mathrm{Fe}^{3+}$ on the $\mathrm{B}$ site cannot be ruled out within the uncertainty of the data. For $\left(\mathrm{Mg}_{0.94} \mathrm{Fe}_{0.06}\right) \mathrm{SiO}_{3}$ perovskite (sample no. 4), we selected a single crystal from the same high-pressure synthesis run and conducted a full structural refinement using SHELXL97 software on X-ray diffraction data collected at ambient conditions using an Oxford Diffraction Xcalibur diffractometer. Details of the structural refinement will be published elsewhere. The refinement showed that all iron occupied the A site exclusively. Electron microprobe data combined with results from Mössbauer spectroscopy gave the following site distribution: $\left[\mathrm{Mg}_{0.946(17)} \mathrm{Fe}^{2+}{ }_{0.045(12)}\right.$ $\left.\mathrm{Fe}^{3+}{ }_{0.008(3)}\right]_{\mathrm{A}}\left[\mathrm{Si}_{0.997(16)} \mathrm{Fe}^{3+}{ }_{0.003(3)}\right]_{\mathrm{B}} \mathrm{O}_{3}$, which means that a small amount of $\mathrm{Fe}^{3+}$ on the $\mathrm{B}$ site cannot be ruled out within the uncertainty of the electron microprobe and Mössbauer data.

SMS spectroscopy. We collected SMS spectra at room temperature and pressures up to $122 \mathrm{GPa}$ using DACs, with or without laser annealing of the samples. SMS spectra of $\mathrm{Mg}_{0.6} \mathrm{Fe}_{0.4} \mathrm{Si}_{0.63}$ $\mathrm{Al}_{0.37} \mathrm{O}_{3}$ perovskite (sample no. 1), which contains iron dominantly as $\mathrm{Fe}^{3+}$, are extremely well resolved (Fig. 1). We fit the data to three quadrupole doublets, one assigned to $\mathrm{Fe}^{3+}$ and two assigned to $\mathrm{Fe}^{2+}$ based on their centre shifts. Visually there appears to be no change to the $\mathrm{Fe}^{3+}$ doublet over the entire pressure range (Fig. 1 and Supplementary Fig. S1).

The hyperfine parameters (centre shift and quadrupole splitting (QS)) for $\mathrm{Fe}^{3+}$ in all samples are the same within experimental error, and there is no change in $\mathrm{Fe}^{3+} / \Sigma \mathrm{Fe}$ for individual samples over the entire pressure range of the experiment (Fig. 2). The hyperfine parameters of the $\mathrm{Fe}^{3+}$ doublet are consistent with the HS state ${ }^{20}$, and their smooth variation with pressure indicates that $\mathrm{Fe}^{3+}$ does not undergo any spin transitions within the entire pressure range. Notably, the QS value proposed for $\mathrm{LS} \mathrm{Fe}^{3+}$ from both experimental ${ }^{6,8}$ and theoretical ${ }^{7}$ studies (red dotted line, Fig. 2a) is more than twice our observed values. The weighted mean QS for $\mathrm{Fe}^{2+}$ in all samples increases dramatically with pressure (Fig. 2b), which arises from a decreasing intensity of the low $\mathrm{QS} \mathrm{Fe}{ }^{2+}$ doublet (blue doublet in Fig. 1) corresponding to the HS state ${ }^{14}$, and an increasing intensity of the high QS doublet (black doublet in Fig. 1), which we assign to the IS state ${ }^{14,15}$.

Our data demonstrate that $\mathrm{Fe}_{\mathrm{A}}^{3+}$ does not undergo a HS to LS transition up to at least $122 \mathrm{GPa}$. This conclusion is in agreement with results from experimental 6,8 and theoretical ${ }^{4,5,7}$ studies. However, several publications ${ }^{6,8,9}$ have suggested that the reduced volume of $\mathrm{LS} \mathrm{Fe}_{\mathrm{B}}^{3+}$ could lead to a redistribution of $\mathrm{Fe}^{3+}$ from the A to the B site in the perovskite structure within the lower mantle. To test this hypothesis, we laser annealed sample no. 2 and 3 at lower-mantle temperatures and a number of pressures and collected SMS spectra both during and after heating. The total duration of heating reached several hours after multiple cycles. Visually, SMS spectra collected after laser annealing showed no change to those taken before heating (Supplementary Fig. S2), and hyperfine parameters remain unchanged (star symbols; Fig. 2). We therefore conclude that there is no exchange of $\mathrm{Fe}^{3+}$ between the $\mathrm{A}$ and the $\mathrm{B}$ site at lower-mantle pressures and temperatures, in agreement with the results of a complementary study using high-pressure single-crystal X-ray diffraction with laser heating undertaken on the same composition as two of our samples ${ }^{19}$.

Electrical conductivity. Electromagnetic induction data offer an important complement to seismic data with respect to lowermantle modelling, because the former are more sensitive to temperature and iron content, whereas the latter better constrain the mineralogy $y^{21}$. Laboratory electrical conductivity data of the relevant minerals are an important component of the approach,

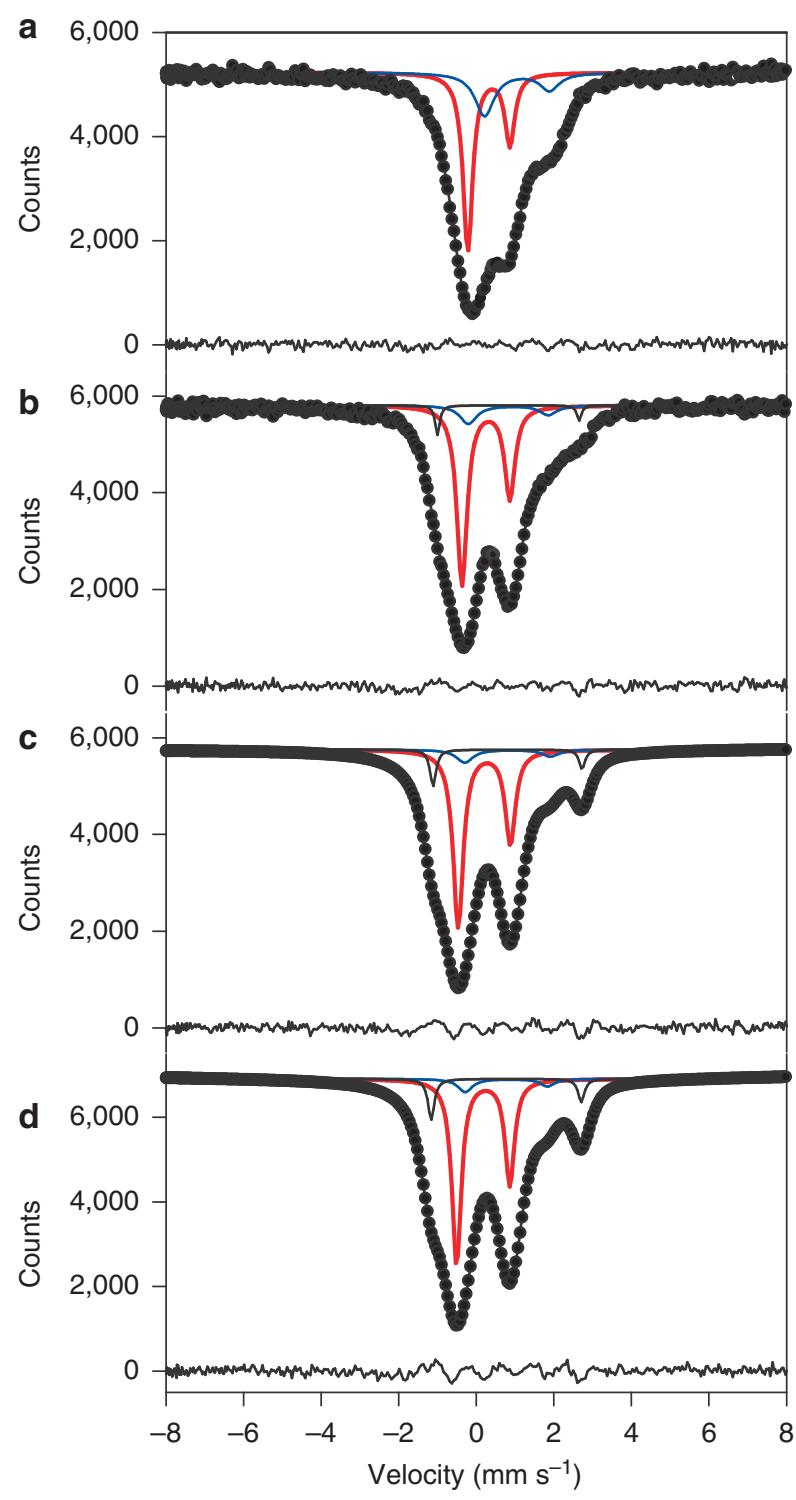

Figure 1 | Influence of pressure on SMS spectra of FeAIPv. Room temperature spectra are shown for $\mathrm{Mg}_{0.6} \mathrm{Fe}_{0.4} \mathrm{Si}_{0.63} \mathrm{Al}_{0.37} \mathrm{O}_{3}$ perovskite sample no. 1 at the following pressures: (a) $2.5 \mathrm{GPa}$; (b) $37.9 \mathrm{GPa}$; (c) $67 \mathrm{GPa}$; and (d) $93 \mathrm{GPa}$. The data were fit to one $\mathrm{Fe}^{3+}$ doublet (red) and two $\mathrm{Fe}^{2+}$ doublets (blue and black), and the fit residual is shown below each spectrum. Area asymmetry is due to preferred orientation of the sample, and the velocity scale is given relative to $\alpha$-iron.

because they provide critical data on how the chemical and thermal state of the material influences the conductivity. Laboratory measurements of single-phase $\mathrm{Mg}_{0.9} \mathrm{Fe}_{0.1} \mathrm{SiO}_{3}$ perovskite ${ }^{10,11}$ and a pyrolite mantle assemblage $e^{12}\left(\mathrm{Fe}^{3+} / \Sigma \mathrm{Fe}\right.$ of the perovskite phase estimated to be $12 \%$ and $30 \%$, respectively $)^{22}$ show a decrease in conductivity $>50 \mathrm{GPa}$, comparable to the electrical conductivity decrease caused by HS-LS spin cross-over of $\mathrm{Fe}^{2+}$ in (Mg,Fe)O (refs 23-25). The drop in silicate perovskite conductivity has been attributed to a HS-LS transition of $\mathrm{Fe}^{3+}$ (refs 10-12); however, this explanation is ruled out by the results in the present work. To investigate the relative contributions of $\mathrm{Fe}^{2+}$ and $\mathrm{Fe}^{3+}$, we measured the electrical resistance of $\mathrm{Mg}_{0.6} \mathrm{Fe}_{0.4} \mathrm{Si}_{0.63} \mathrm{Al}_{0.37} \mathrm{O}_{3}$ perovskite $(93 \%$ $\mathrm{Fe}^{3+} / \Sigma \mathrm{Fe}$ ) at high pressure and high temperature, which shows a smooth decrease with increasing pressure (Fig. 3a). This decrease 

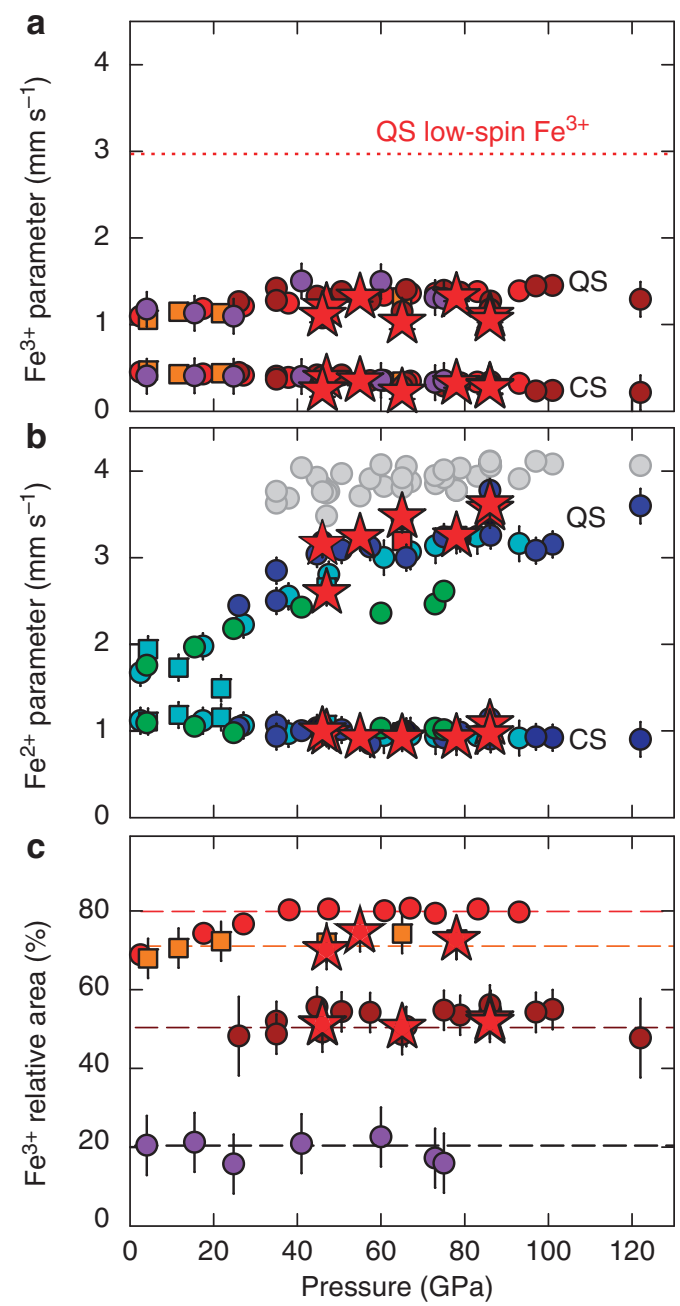

Figure 2 | Pressure variation of FeAIPv hyperfine parameters.

Values of centre shift (CS) and quadrupole splitting (QS) are shown for (a) $\mathrm{HS} \mathrm{Fe}^{3+}$ and (b) $\mathrm{Fe}^{2+}$. Sample data are indicated as follows: $\mathrm{Mg}_{0.6} \mathrm{Fe}_{0.4} \mathrm{Si}_{0.63} \mathrm{Al}_{0.37} \mathrm{O}_{3}$ perovskite sample no. 1 (red and light blue circles); $\mathrm{Mg}_{0.6} \mathrm{Fe}_{0.4} \mathrm{Si}_{0.63} \mathrm{Al}_{0.37} \mathrm{O}_{3}$ perovskite sample no. 2 (orange and light blue squares); $\mathrm{Mg}_{0.83} \mathrm{Fe}_{0.2} \mathrm{Al}_{0.06} \mathrm{Si}_{0.91} \mathrm{O}_{3}$ perovskite sample no. 3 (brown and dark blue circles); and $\mathrm{Mg}_{0.94} \mathrm{Fe}_{0.06} \mathrm{SiO}_{3}$ perovskite sample no. 4 (purple and green circles). The expected QS for $\mathrm{LS} \mathrm{Fe}^{3+}$ is shown as a horizontal red dotted line. Hyperfine parameters for $\mathrm{Fe}^{2+}$ are shown as weighted averages of the two doublets (colours as above) and QS for the high $\mathrm{QS} \mathrm{Fe}{ }^{2+}$ doublet (grey circles). (c) Pressure variation of $\mathrm{Fe}^{3+} / \Sigma \mathrm{Fe}$ as determined from the relative areas in silicate perovskite Mössbauer spectra: sample no. 1 (red circles); sample no. 2 (orange squares); sample no. 3 (brown circles); and sample no. 4 (purple circles). Horizontal lines are guides for the eye. Values obtained after laser heating of samples 2 and 3 are indicated by red stars. Error bars represent $2 \sigma$ uncertainty based on fitting statistics. In all cases, parameters remained unchanged from those before heating within experimental error, demonstrating that there is no $\mathrm{HS}$ to $\mathrm{LS}$ transition in $\mathrm{Fe}^{3+}$ at the pressure-temperature conditions of the lower mantle.

corresponds to a smooth increase in electrical conductivity with pressure, in contrast to the large drop seen in samples dominated by $\mathrm{Fe}^{2+}$ (Fig. 3b). Such behaviour strongly suggests that the conductivity drop in samples dominated by $\mathrm{Fe}^{2+}$ is due to the HS to IS transition in $\mathrm{Fe}^{2+}$, where electron mobility is reduced due to the spin transition, analogous to the behaviour of $(\mathrm{Mg}, \mathrm{Fe}) \mathrm{O}^{23-25}$. The greater drop at high temperature (brown

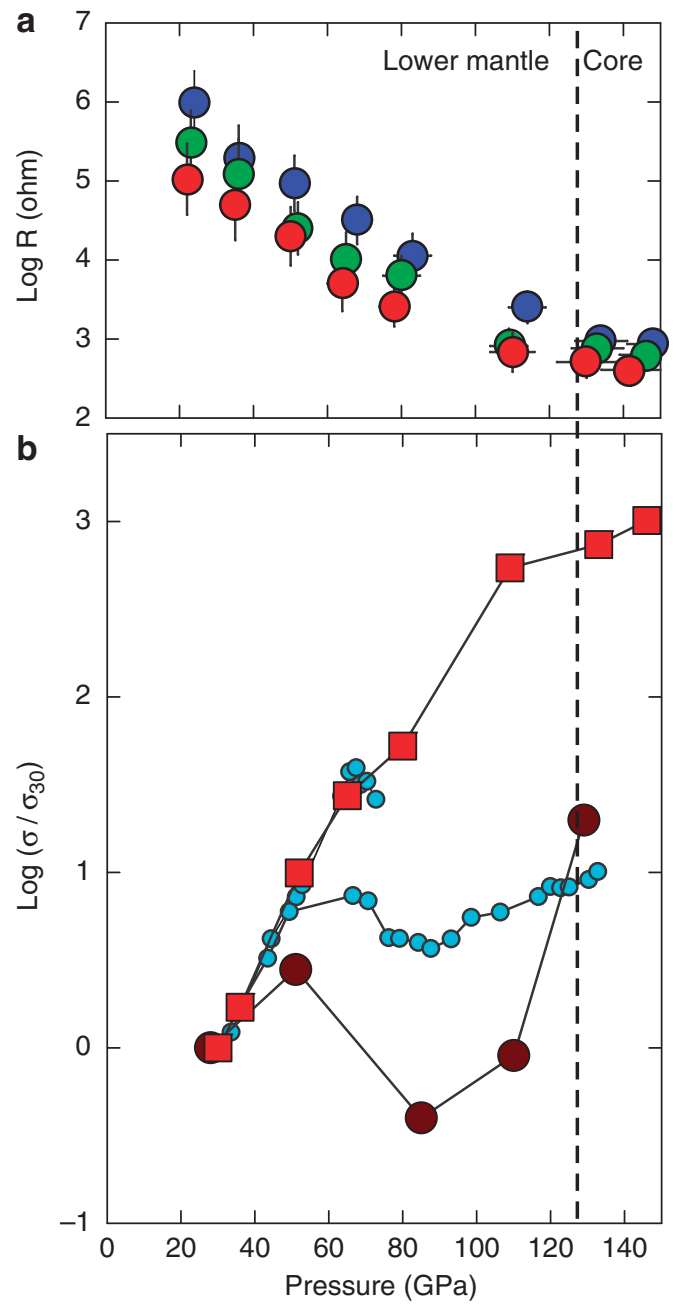

Figure 3 | Electrical properties of FeAIPv as a function of pressure.

(a) Influence of pressure on the electrical resistance of

$\mathrm{Mg}_{0.60} \mathrm{Fe}_{0.40} \mathrm{Si}_{0.63} \mathrm{Al}_{0.37} \mathrm{O}_{3}$ perovskite $\left(\mathrm{Fe}^{3+} / \Sigma \mathrm{Fe}=0.93 \pm 0.3\right)$ measured using a laser-heated DAC at different temperatures: blue $-1250 \pm 50 \mathrm{~K}$; green $-1800 \pm 50 \mathrm{~K}$; red $-2300 \pm 100 \mathrm{~K}$. Error bars represent $2 \sigma$ uncertainty of the measurement value. (b) Relative change of electrical conductivity of FeAIPv as a function of pressure calculated from resistance data. Red squares indicate new data for $\mathrm{Mg}_{0.6} \mathrm{Fe}_{0.4} \mathrm{Si}_{0.63} \mathrm{Al}_{0.37} \mathrm{O}_{3}$ perovskite $\left(\mathrm{Fe}^{3+} / \Sigma \mathrm{Fe} \sim 93 \%\right)$ collected at $1800 \mathrm{~K}$. Also shown are two sets of literature data for $\mathrm{Mg}_{0.9} \mathrm{Fe}_{0.1} \mathrm{SiO}_{3}$ perovskite $\left(\mathrm{Fe}^{3+} / \Sigma \mathrm{Fe} \sim 12 \%\right)$ at room temperature (blue circles) ${ }^{11}$ and a pyrolite assemblage $\left(\mathrm{Fe}_{\mathrm{pv}}^{3+} / \Sigma \mathrm{Fe}_{\mathrm{pv}}\right.$ $\sim 30 \%)^{22}$ at $1800 \mathrm{~K}$ (brown circles) ${ }^{12}$. Data are plotted relative to the values at $30 \mathrm{GPa}\left(\sigma_{30}\right)$. The error bars representing the precision of the data from this work are smaller than the symbols (red squares).

circles in Fig. 3b) is consistent with the increasing stability of the IS state with temperature ${ }^{14,15}$.

\section{Discussion}

Previously temperature and total iron content have been considered to have the greatest influence on lower-mantle electrical conductivity profiles ${ }^{21}$, but our data show that $\mathrm{Fe}^{3+}$, $\Sigma \mathrm{Fe}$ could also affect conductivity significantly at mid-mantle depths $(1200-1900 \mathrm{~km})$. A companion work has shown that $\mathrm{Fe}^{3+} / \Sigma \mathrm{Fe}$ could also affect bulk sound velocity in the lower mantle ${ }^{19}$; hence, joint inversion of electromagnetic and seismic data based on these new data could yield results different to currently accepted views. For example the superadiabatic 
temperature gradient inferred for the lower mantle from such a joint inversion ${ }^{21}$ may not be required due to the reduced electrical conductivity of silicate perovskite resulting from the HS-IS transition. Three-dimensional inversions of electromagnetic data are now possible, and show variations of more than one order of magnitude in electrical conductivity, many of which are correlated with fast and slow regions of seismic tomography models ${ }^{26}$. Our new data suggest that for silicate perovskite with lower-mantle composition, a lower $\mathrm{Fe}^{3+} / \Sigma \mathrm{Fe}$ ratio will cause lower conductivity (reduction of conductivity due to the $\mathrm{Fe}^{2+}$ HS-IS transition) and a higher bulk sound velocity ${ }^{19}$. Indeed many regions were found to show such a correlation ${ }^{26}$, which could be indicative of bulk mantle properties away from areas associated with subduction.

In conclusion, based on novel SMS data we have demonstrated the absence of a spin transition of $\mathrm{Fe}^{3+}$ in FeAlPv at pressures and temperatures corresponding to those in the lower mantle. Electrical conductivity measurements of $\mathrm{Fe}^{3+}$-rich FeAlPv show no evidence for the conductivity drop previously observed in $\mathrm{Fe}^{2+}$-rich FeAlPv compositions, suggesting that the conductivity drop is due to the reduced mobility of electrons caused by a HS-IS transition of $\mathrm{Fe}^{2+}$. Combined with recent results reporting the influence of $\mathrm{Fe}^{3+}$ on elastic wave velocities of FeAlPv, our results may provide improved constraints for forward modelling of electromagnetic data as well as for joint inversion of electromagnetic and seismic data, potentially providing a new probe of heterogeneity in the lower mantle.

\section{Methods}

Synchrotron Mössbauer source. A SMS provides a high-brilliance beam of synchrotron radiation with an energy bandwidth of $\sim 20 \mathrm{neV}$. The SMS beam is polarized up to $99 \%$, and it consists $100 \%$ of recoilless radiation with zero background. These properties enable rapid and precise measurements of Mössbauer spectra of samples under extreme conditions. The possibility to develop such a source was first demonstrated at the Nuclear Resonance beamline ID18 (ref. 27) at the European Synchrotron Radiation Facility in 1997 (ref. 28), and technical details of the configuration used in the present work are given in Potapkin et al. ${ }^{18}$ )

${ }^{57} \mathrm{Fe}$ SMS spectra were collected on the nuclear resonance beamline ID18 at the European Synchrotron Radiation Facility during operation in multibunch mode $\left(7 / 8+1\right.$ filling) with the beam focused to roughly $10 \times 10 \mu \mathrm{m}^{2}$ using KirkpatrickBaez multilayer optics. During the SMS experiment, the linewidth of the source was controlled before and after each sample measurement using $\mathrm{K}_{2} \mathrm{Mg}^{57} \mathrm{Fe}(\mathrm{CN})_{6}$, whose Mössbauer spectrum consists of a single line, and the velocity scale was calibrated using $25-\mu \mathrm{m}$ thick natural $\alpha$-iron foil. SMS spectra were collected over $10-60 \mathrm{~min}$ each. Spectra were fitted using the program Moss $\mathrm{A}^{29}$, which takes into account the Lorentzian-squared source instrumental function ${ }^{30}$. The dimensionless effective Mössbauer thicknesses were approximately 40 and 20 for the $\mathrm{Mg}_{0.6} \mathrm{Fe}_{0.4} \mathrm{Si}_{0.63} \mathrm{Al}_{0.37} \mathrm{O}_{3}$ perovskite sample no. 1 and 2 , and 8 and 3 for the $\mathrm{Mg}_{0.83} \mathrm{Fe}_{0.2} \mathrm{Al}_{0.06} \mathrm{Si}_{0.91} \mathrm{O}_{3}$ and $\mathrm{Mg}_{0.94} \mathrm{Fe}_{0.06} \mathrm{SiO}_{3}$ perovskite samples, respectively.

Sample synthesis. All silicate perovskite samples were synthesized using a multianvil press. The experiments were performed using $\mathrm{Cr}_{2} \mathrm{O}_{3}$-doped $\mathrm{MgO}$ octahedra fitted with a $\mathrm{LaCrO}_{3}$ heater in combination with tungsten carbide cubes following the methodology described in Keppler and Frost ${ }^{31}$. Chemical compositions were measured using an electron microprobe (S4949 and S5083) or estimated based on electron microprobe measurements of a sample synthesied under the same conditions in a different run (S4850). Details of each experiment are given in Table 1.

DAC experiments. Samples for DAC experiments were carefully selected from the run products to be homogeneous under an optical microscope. Small plate-like pieces of the material (typical dimensions $\sim 30 \times 30 \times 15 \mu \mathrm{m}^{3}$ ) were loaded together with ruby chips (pressure marker) into the sample chambers of DACs available at Bayerisches Geoinstitut. Diamonds with culets of diameter 120, 250 and $300 \mu \mathrm{m}$ were used in different experiments depending on the pressure range. The sample chamber was prepared by drilling a hole in a pre-indented rhenium gasket, and the hole was filled with the sample material and the quasi-hydrostatic pressure medium, Ne.

We used a modified and enhanced version of the portable laser heating setup described previously ${ }^{32,33}$. The setup was installed on beamline ID18 and consists of a SPI laser system (SPI100, wavelength $1064 \mathrm{~nm}, 100 \mathrm{~W}$ ) coupled by an optical fibre to a UniHead system, which allows simultaneous visual observation of the sample, laser heating and evaluation of temperature. In order to ensure homogeneous heating of the samples, a laser spot with a diameter of about $50 \mu \mathrm{m}$ was used. In order to guarantee homogeneous heating, we flattened the power profile of the laser beam using a special optical device ( $\pi$-shaper) mounted on the UniHead.

Samples 2 and 3 were heated for a total of several hours in multiple cycles during continuous laser operation mode. Thermal radiation from the heated sample was collected by an Ocean Optics QE65000 spectrometer, and the resulting spectra were fitted to the Planck radiation function ${ }^{34}$, which gave temperatures between 2000 and $2400 \mathrm{~K}$

SMS spectrum fitting. SMS spectra can be fitted using the same approach for conventional energy-domain Mössbauer spectra provided the following criteria are met: (a) the source lineshape is implemented as a normalized squared Lorentzian (instead of a normalized Lorentzian) ${ }^{30}$; (b) the full transmission integral is used to fit the data because of the high absorption and the lack of non-resonant background; and (c) component areas of doublets and sextets are not fixed to ideal values (that is, 1:1 for quadrupole doublets and 3:2:1:1:2:3 for magnetic sextets) because of the polarized nature of the synchrotron source combined with the tendency for preferred orientation in the DAC.

We fit all of the SMS spectra to three quadrupole doublets, one with small centre shift (average value $\sim 0.35 \mathrm{~mm} \mathrm{~s}^{-1}$ ) corresponding to $\mathrm{Fe}^{3+}$, and two with larger centre shift (average value $\sim 1 \mathrm{mms}^{-1}$ ) corresponding to $\mathrm{Fe}^{2+}$. We applied the conventional constraint of equal widths but allowed the area ratios of component doublets to vary, with all area ratios of doublets within a single spectrum constrained to be the same based on the reasonable assumption that the principal directions of the electric-field gradient for both the A and the B sites are the same based on the crystallography of the perovskite structure.

Electrical conductivity measurements. Resistance measurements were conducted at high pressure and high temperature on a sample of $\mathrm{Mg}_{0.60} \mathrm{Fe}_{0.40} \mathrm{Si}_{0.63} \mathrm{Al}_{0.37} \mathrm{O}_{3}$ perovskite $\left(\mathrm{Fe}^{3+} / \Sigma \mathrm{Fe}=0.93 \pm 0.3\right)$ that was synthesized in a multianvil run using the same starting materials and at the same conditions as samples 1 and 2 . We used a BX90-type DAC ${ }^{35}$ where a standard brilliant cut diamond with $400 \mu \mathrm{m}$ culet was used as the first anvil, and a conventional beveled diamond with $120 \mu \mathrm{m}$ culet was used as the second anvil. To prepare the gasket, a $50-\mu \mathrm{m}$ diameter hole was drilled in a $25-\mu \mathrm{m}$ thick piece of rhenium foil, after which the drilled piece of rhenium was cut into two halves using a near-infrared laser with the cutting plane passing through the middle of the hole. The two rhenium foil halves were coated with a gold layer roughly $2-\mu \mathrm{m}$ thick using a simple sputter coater and then glued onto a synthetic single-crystal diamond, thus providing a split-gasket hole configuration for the sample chamber. A platinum wire with $20 \mu \mathrm{m}$ diameter was used in a linear four-point probe scheme (see Kuznetsov et al. ${ }^{36}$ for technical details). Current was supplied through two platinum leads glued onto different halves of the split gasket, and voltage was measured using the other two leads. The particular construction of the DAC used enabled the platinum leads from the gasket to emerge freely from the DAC to then be connected to measuring devices, whereas thin ceramic tubes prevented potential contact of the platinum wires with the metallic body of the DAC. Small pieces of sample roughly $10-12 \mu \mathrm{m}$ in diameter and $5-7-\mu \mathrm{m}$ thick were loaded into the middle of the split-gasket hole. Synthetic diamond powder (grain size $<1 \mu \mathrm{m}$ ) placed in the slits between the halves of the split gasket provided reliable insulation of the two halves of the gasket, whereas the sample in the split-gasket hole closed the circuit. The current and voltage measurements were read out using multimeters. The sample was heated using a portable laser heating system as previously described ${ }^{32}$.

Resistance data were collected at pressures up to $146 \mathrm{GPa}$ at three different temperatures $\left(1250,1800\right.$ and $2300 \mathrm{~K}$ ). The quantity $\sigma / \sigma_{30}$ (that is, the electrical conductivity relative to the value at $30 \mathrm{GPa}$ ) was calculated based on the change in height of the sample as a function of pressure that was measured in a separate experiment.

\section{References}

1. McCammon, C. A. Perovskite as a possible sink for ferric iron in the lower mantle. Nature 387, 694-696 (1997).

2. Frost, D. J. et al. Experimental evidence for the existence of iron-rich metal in the Earth's lower mantle. Nature 428, 409-411 (2004).

3. McCammon, C. A. The paradox of mantle redox. Science 308, 807-808 (2005).

4. Zhang, F. \& Oganov, A. R. Valence state and spin transitions of iron in Earth's mantle silicates. Earth Planet. Sci. Lett. 249, 436-443 (2006).

5. Stackhouse, S., Brodholt, J. P. \& Price, G. D. Electronic spin transitions in iron-bearing $\mathrm{MgSiO}_{3}$ perovskite. Earth Planet. Sci. Lett. 253, 282-290 (2007).

6. Catalli, K. et al. Spin state of ferric iron in $\mathrm{MgSiO}_{3}$ perovskite and its effect on elastic properties. Earth Planet. Sci. Lett. 289, 68-75 (2010).

7. Hsu, H., Blaha, P., Cococcioni, M. \& Wentzcovitch, R. M. Spin-state crossover and hyperfine interactions of ferric iron in $\mathrm{MgSiO}_{3}$ perovskite. Phys. Rev. Lett 106, 118501 (2011).

8. Catalli, K. et al. Effects of the $\mathrm{Fe}^{3+}$ spin transition on the properties of aluminous perovskite - New insights for lower-mantle seismic heterogeneities. Earth Planet. Sci. Lett. 310, 293-302 (2011). 
9. Fujino, K. et al. Spin transition of ferric iron in Al-bearing Mg-perovskite up to $200 \mathrm{GPa}$ and its implication for the lower mantle. Earth Planet. Sci. Lett. 317-318, 407-412 (2012).

10. Ohta, K. et al. The electrical conductivity of post-perovskite in Earth's D" layer. Science 320, 89-91 (2008).

11. Ohta, K., Hirose, K., Shimizu, K., Sata, N. \& Ohishi, Y. The electrical resistance measurements of $(\mathrm{Mg}, \mathrm{Fe}) \mathrm{SiO}_{3}$ perovskite at high pressures and implications for electronic spin transition of iron. Phys. Earth Planet. Int. 180, 154-158 (2010).

12. Ohta, K. et al. Electrical conductivities of pyrolitic mantle and MORB materials up to the lowermost mantle conditions. Earth Planet. Sci. Lett. 289, 497-502 (2010).

13. Badro, J. et al. Electronic transitions in perovskite: Possible non-convecting layers in the lower mantle. Science 305, 383-386 (2004).

14. McCammon, C. et al. Stable intermediate-spin ferrous iron in lower mantle perovskite. Nat. Geosci. 1, 684-687 (2008).

15. Lin, J.-F. et al. Intermediate-spin ferrous iron in lowermost mantle post-perovskite and perovskite. Nat. Geosci. 1, 688-691 (2008).

16. Hsu, H., Umemoto, K., Blaha, P. \& Wentzcovitch, R. M. Spin states and hyperfine interactions of iron in $(\mathrm{Mg}, \mathrm{Fe}) \mathrm{SiO}_{3}$ perovskite under pressure. Earth Planet. Sci. Lett. 294, 19-26 (2010).

17. Smirnov, G. V., Chumakov, A. I., Potapkin, V. B., Rüffer, R. \& Popov, S. L. Multispace quantum interference in a ${ }^{57} \mathrm{Fe}$ synchrotron Mössbauer source. Phys. Rev. A 84, 053851 (2011).

18. Potapkin, V. et al. The ${ }^{57} \mathrm{Fe}$ synchrotron Mössbauer source at the ESRF. J. Synchrotron Radiat. 19, 559-569 (2012).

19. Glazyrin, K. Iron in oxides, silicates and alloys under extreme pressuretemperature conditions. $\mathrm{PhD}$ thesis, Univ. Bayreuth (2011).

20. Greenwood, N. N. \& Gibb, T. D. Mössbauer Spectroscopy (Chapman and Hall, 1971).

21. Verhoeven, O. et al. Constraints on thermal state and composition of the Earth's lower mantle from electromagnetic impedances and seismic data. J. Geophys. Res. 114, B03302 (2009).

22. McCammon, C. A., Lauterbach, S., Seifert, F., Langenhorst, F. \& van Aken, P. A. Iron oxidation state in lower mantle mineral assemblages I. Empirical relations derived from high-pressure experiments. Earth Planet. Sci. Lett. 222, 435-449 (2004)

23. Lin, J.-F. et al. Electrical conductivity of the lower-mantle ferropericlase across the electronic spin transition. Geophys. Res. Lett. 34, L16305 (2007).

24. Ohta, K., Hirose, K., Onoda, S. \& Shimizu, K. The effect of iron spin transition on electrical conductivity of (Mg,Fe)O magnesiowüstite. Proc. Japan Acad. Ser. B 83, 97-100 (2007).

25. Yoshino, T. et al. Effect of iron content on electrical conductivity of ferropericlase with implications for the spin transition pressure. Geophys. Res. Lett. 116, B04202 (2011).

26. Tarits, P. \& Mandéa, M. The heterogeneous electrical conductivity structure of the lower mantle. Phys. Earth Planet. Int. 183, 115-125 (2010).

27. Rüffer, R. \& Chumakov, A. I. Nuclear resonance beamline at ESRF. Hyperfine Interact. 97/98, 589-604 (1996).

28. Smirnov, G. V., van Bürck, U., Chumakov, A. I., Baron, A. Q. R. \& Rüffer, R. Synchrotron Mössbauer source. Phys. Rev. B 55, 5811-5815 (1997).
29. Prescher, C., McCammon, C. \& Dubrovinsky, L. MossA-a program for analyzing energy-domain Mossbauer spectra from conventional and synchrotron sources. J. Appl. Crystallogr. 45, 329-331 (2012).

30. Potapkin, V. B. et al. Angular, spectral and temporal properties of nuclear radiation from the ${ }^{57} \mathrm{Fe}$ Synchrotron Mössbauer source. Phys. Rev. A 86, 053808 (2012).

31. Keppler, H. \& Frost, D. J. in Mineral Behaviour at Extreme Conditions Vol. 7 EMU Notes in Mineralogy (ed. Miletich, R.) 1-30 (Eötvös University Press, 2005).

32. Dubrovinsky, L. et al. Portable laser-heating system for diamond anvil cells. J. Synchrotron Radiat. 16, 737-741 (2009).

33. Dubrovinsky, L. et al. Single-crystal X-ray diffraction at megabar pressures and temperatures of thousands of degrees. High Pressure Res. 30, 620-633 (2010).

34. Bassett, W. A. \& Weathers, M. Temperature measurement in laser heated diamond anvil cells. Physica B + C 139-140, 900-902 (1986).

35. Kantor, I. et al. BX90: A new diamond anvil cell design for X-ray diffraction and optical measurements. Rev. Sci. Instrum. 83, 125102 (2012).

36. Kuznetsov, A. Y. et al. In-situ combined X-ray diffraction and electrical resistance measurements at high pressures and temperatures in diamond anvil cells. High Pressure Res. 27, 213-222 (2007).

\section{Acknowledgements}

We thank the European Synchrotron Radiation Facility for provision of synchrotron radiation (ID18). We also thank Jean-Philippe Celse for additional technical assistance, Ilya Sergueev for help with data analysis software, Dan Frost for the synthesis of sample S4850 and Dan Frost and Yoichi Nakajima for their additional assistance with multianvil experiments. The project was supported by funds from the German Science Foundation (DFG) in their normal funding programme and Priority Programme SPP1236, the PROCOPE exchange programme and the German Federal Ministry for Education and Research (BMBF)

\section{Author contributions}

The methodology was developed by G.V.S., V.P., A.I.C. and R.R., and the research project was designed and directed by C.M. and L.D. Samples were synthesized by R.S and characterized by R.S., K.G., L.D., V.P. and C.M. The data were collected and analysed by V.P., C.M., L.D., K.G., A.K., I.K., C.P., R.S. and A.I.C. All authors were involved in the data interpretation. The manuscript was written by V.P. and C.M. with contributions from all co-authors.

\section{Additional information}

Supplementary Information accompanies this paper on http://www.nature.com/ naturecommunications

Competing financial interests: The authors declare no competing financial interests.

Reprints and permission information is available online at http://npg.nature.com/ reprintsandpermissions/

How to cite this article: Potapkin, V. et al. Effect of iron oxidation state on the electrical conductivity of the Earth's lower mantle. Nat. Commun. 4:1427 doi: 10.1038/ ncomms2436 (2013). 